\section{Consortium aims to revive sterile-mosquito project}

[HYDERABAD, INDIA] A controversial USfunded mosquito-control project in Delhi which was closed down by the Indian government 20 years ago (Nature 256, 355-357; 1975) is now likely to be revived.

International efforts are under way to relaunch a sterile-insect technology (SIT) project, despite scepticism in parts of India's scientific community, with the aim of eradicating Anopheles stephensi - the principal vector for urban malaria — from towns in southern India.

SIT relies on the fact that female mosquitoes mate only once. If this single mating occurs with sterilized males, it results in eggs that do not hatch. So releasing sterilized males in numbers far greater than those of the wild male population could eradicate the targeted vector mosquitoes - provided the area is not reinfested by mosquitoes from the surrounding region.

The move to revive the technique is being led by Christopher Curtis of the London School of Hygiene and Tropical Medicine, Alan Robinson, head of the entomology unit of the Vienna-based International Atomic Energy Agency (IAEA), and Vinod Prakash Sharma, who is due to retire shortly as director of India's Malaria Research Centre (MRC) in New Delhi.

The group presented the idea to last month's global meeting on malaria in Hyderabad, sponsored by the Malaria Foundation, which is based in New York. They are also preparing a report on it for India's Department of Biotechnology, which is said to be sympathetic to the project, provided that environmental and biosafety concerns are met.

Both Curtis and Sharma were prominent scientists of the Delhi project that was terminated in 1975 following an uproar in the Indian parliament about reports that the project was part of US efforts to develop yellow fever as a biological weapon.

These allegations were prompted by the fact that project scientists had been genetically manipulating the Aedes aegypti mosquitoes which spread yellow fever — a disease that does not exist in India — and were planning a massive release of sterile males of this species.

Curtis denies that anything sinister took place, and says that the project fell victim to an "ill-informed press and political campaign". The new project proposed for southern India will use mosquitoes sterilized by radiation and will not involve genetic manipulation.

Robinson says the IAEA, with backing from the World Health Organization and the

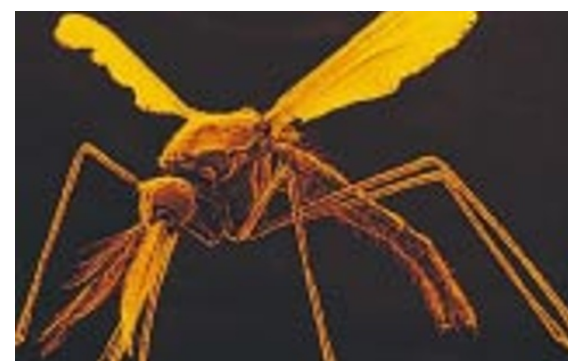

Pointed problem: a male specimen of Anopheles.

United States, plans to raise the $\$ 12$ million needed to start the project by holding a series of donor meetings, and to start work next year. Meanwhile, the search is on for an Indian scientist to act as local project leader.

Curtis says that towns such as Salem, in the state of Tamil Nadu in southern India, are ideal sites for SIT because A. stephensi, the only vector spreading malaria in these towns, is totally absent in surrounding rural areas. "If we get rid of $A$. stephensi in towns using SIT, no replacement is possible and the area can remain free of malaria for ever," he says.

Some scientists are sceptical, however, citing potential problems with cost, efficiency of separation of the sexes, and what they predict would be the temporary nature of any eradication. "This technology is not workable," warns P. K. Rajagopalan, the former director of the Vector Control Research Centre in Pondicherry, who was involved in the Delhi project. "It is a mystery to me why it is coming back after two decades." P. K. Das, current director of the Pondicherry centre, says India does not need high-technology mosquito control. "What we need is political will to implement low-cost techniques that already exist," he says.

It is true that the long-term efficacy of SIT in eradicating mosquitoes has not been demonstrated. But Robinson says that recent success in controlling screw worm, tsetse and Mediterranean fruitflies "gives us hope we can use this technology in human health".

On the question of separation of the sexes - no females can be released because they are the ones that bite - Robinson also argues that techniques for sexing Anopheles mosquitoes have been refined. He says he is confident that "the changed political atmosphere in India" will not allow the 1975 episode to be repeated.

And on the third argument, cost, an official from the MRC told the Hyderabad malaria conference: "Delhi spends \$9 million each year on malaria control without any success. Can't we spend this money just once to eliminate the malaria mosquitoes for ever, using SIT?"

K.S.Jayaraman

\section{US patent office withdraws patent on Indian herb}

[NEW DELHI] India has forced the US Patent and Trademark Office (PTO) to revoke a contentious patent it granted two years ago to researchers in the United States on the use of powdered turmeric (Curcuma longa) for wound healing.

The PTO withdrew the patent on 13 August after a year-long legal battle with India's Council of Scientific and Industrial Research (CSIR), which argued that turmeric, a native Indian plant, had been used for centuries by its people for wound healing, and so lacked the "novelty" criterion required for patenting.

The Indian agency hired a US patent lawyer and spent $\$ 15,000$ to fight the case, which it supported with documents ranging from scientific publications to books on home remedies and ancient Ayurvedic texts on Indian systems of medicine.

Indian scientists claim this is the first time that a move in the United States to patent a traditional remedy from the developing world has been successfully overturned. Earlier efforts by an international coalition of environmentalists to get the US patents on products of the neem tree cancelled ended in failure (Nature 377, 95; 1995).

The CSIR's director, Ragunath Mashelkar, said the success of the case had far-reaching consequences for the protection of the traditional knowledge base, "not only in India but in other Third World countries". He said the case also highlights the importance of documenting traditional knowledge, to provide evidence of prior knowledge.

The turmeric patent was granted in 1995 to two researchers, Soman K. Das and Harihar Kohli of the University of Mississippi Medical Center. Their six patent claims covered the oral and topical use of turmeric powder to heal surgical wounds and ulcers. Das and Kohli contested CSIR's objections, but the patent office rejected all their claims.

The patenting of traditional remedies from developing countries became a global issue after patents were granted for neem. These patents were upheld because they covered novel processes for increasing the useful life of azadirachtin, neem's active ingredient.

Mashelkar says that India fought the turmeric patent not for financial reasons, but to uphold "national pride" and to dispel unfounded fears that India was incapable of protecting its traditional knowledge base.

In cooperation with other agencies, the CSIR has already launched a programme to analyse 490 medicinal plants and place the information on CD-ROM. This will be made available to European and US patent offices as a reference guide. 